\title{
PREFACE
}

Primitivism was an aesthetic project formed in reaction to the zenith of imperialist expansion at the start of the twentieth century. As those spaces in which "primitive" modes of existence were imagined to be possible either were directly colonized or otherwise forcibly integrated into a geographically totalized capitalist system, so dissenting spirits responded by trying to rekindle the primitive by means of their art. As such, primitivism was a project specific to this world-historical situation: an undertaking to become primitive in a world where, it seemed, such a possibility had been voided.

The "primitive" condition toward which primitivist works aspire thus is constitutively speculative. Where once archaeology, history, travel reportage (including artistic impressions), and later ethnology had seemed to bring to those residing in "civilization" knowledge about those leading supposedly "primitive" forms of life, the global saturation of that form of "civilization," modern capitalism, meant that the "primitive" had either been lost or become irredeemably mediated (that is, no longer primitive). If the idealization of the primitive, what this study calls philo-primitivism, previously had tended to take the form of a fixed representation, with the onset of the conditions that gave rise to primitivism, it fell to the transformative capacity of art to make possible the incarnation of the primitive and the restoration of immediate experience.

The primitivist project was not restricted to Western artists, which is to say, those situated in or near the metropolitan centers of the capitalist worldsystem. It was an aesthetic mode taken up across its span. Indeed, artists from 
colonized peripheral societies were the ones who most keenly felt the loss of unalienated social worlds, and it was they who most energetically pursued an aesthetics of immediacy. The most intensively primitivist works were written by the Martinican Aimé Césaire.

\section{I I}

Such is the understanding of primitivism advanced in the following study. Those familiar with the term and its usage in humanistic scholarship will recognize immediately that this understanding is at odds with the conventional view. Primitivism usually is considered as "the idealization of the idea of the primitive," and, in theory, it is a mode of idealization that can take hold in any given "civilized" society. In practice, though, it is thought to be a peculiarity of the modern "West," whatever that civilizational entity is reckoned to be. Scholarly effort thus has been directed at trying to work out why the advent of modern Western civilization should have prompted this kind of idealization. In recent years these questions have been posed almost exclusively in terms of ideology and discourse. Primitivism has been regarded as a unidirectional ideological projection from the colonizer onto the colonized: a racial and imperialistic "discourse" according to which Western artists and thinkers idealize those non-Western peoples whom they suppose to be "primitive." There were good reasons for this turn to discourse and ideology, especially in view of the undeniably racial character of the phenomenon. Naive assumptions about primitivism's good intentions were banished and its appropriative impulse exposed. It was cast from its once heroic place in the narrative of aesthetic modernism, especially in the visual arts, and the primitivist work of revered artists like Pablo Picasso and D. H. Lawrence came to be regarded with suspicion if not contempt. Lawrence's reputation, for one, has not recovered.

The purpose of this study is not to revisit primitivism thought of in such terms. It is, rather, to change the object. The assumptions that underpin the now conventional understanding of primitivism need to be interrogated in the light of methodological developments in literary studies and its significance reappraised. Most significantly, recent efforts to understand the systemic integration of literary cultures can help to open our eyes to the global nature of this aesthetic mode and to perceive that it was an aspiration in both the "West" and "non-West" (categories that this study will treat with a high degree of skepticism). A pariah term in recent scholarship, the idea that primitivism was only an ideological projection of those from the center of empire has meant that its most 
powerful expressions in the peripheries either have been overlooked or miscast as second-order appropriations. However vexed, primitivism holds an important place in the utopian memory of attempts to negate the social logic of globalizing capital. To recover primitivism's aesthetic force and political horizon, this study dismantles the reigning assumptions surrounding the concept before exploring the theoretical and interpretative possibilities made available by doing so.

Accordingly, the book is arranged into two parts. In the first part I revisit the scholarly debates concerning primitivism that have lain dormant for some years and set out the theoretical claims and historical argument that will enable us to reconceive of primitivism as an aesthetic phenomenon specific to the period of finance-driven imperialism. In the second part I undertake three detailed studies of literary primitivism, centered on the work of Aimé Césaire, D. H. Lawrence, and Claude McKay, respectively. This book does not chart a "rise and decline" chronological story, nor does it attempt a survey of literary works that might be regarded as primitivist. My central purpose is to make primitivism as present to readers as possible, working outward from its epicenter. It is only after we appreciate what Césaire achieved that we can get a firm hold on what was going on in the earlier primitivist efforts of Lawrence and McKay (and thence other primitivist works). The book's conclusion reflects on the politics of primitivism, especially what I will call its decolonial horizon, and asks in what respects we might consider this global aesthetic phenomenon to be a manifestation of world literature.

The intellectual mood that has given rise to the recent resurgence of the concept of "world literature" has also given impetus to my revisionist thesis. This is not, though, a study of primitivism and/as world literature. Rather, it is motivated by the return of what György Lukács called the "point of view of totality" to literary scholarship; more especially, it participates in the attempt to understand the purpose of literature in a capitalist world-system marked by the uneven and combined development of its constituent parts. ${ }^{1}$ To think in terms of totality is to approach social phenomena as interrelated parts of a dialectically evolving whole. This is crucial for our understanding of both terms in the compound literary primitivism. It could not have manifested itself across the breadth of the world-system had there not been (1) a general sense that the space of the "primitive" had been colonized once and for all and (2) a pervasive belief in the transformative agency of aesthetic practice. The latter is what gave the primitivist project its method. Primitivists turned to the illusory and speculative capacity of artworks to reanimate the primitive remnant and reawaken the possibility of a social reconciliation with nature. 
This study focuses on literary works, but its basic thesis pertains to primitivism across aesthetic media. Where postmodern critics interrogated primitivist discourse with little regard for the kinds of texts and objects in which it appeared, I am concerned with the specific potentialities of aesthetic materials. Owing to its inherently speculative nature, the wish for the primitive could only be realized in the kinesis of aesthetic making-by which I am referring to that manipulation of language that animates an image or notion and gives shape to literary form, or that activation of the enabling limits of genre so that an illusion might achieve presence. Primitivism, in short, does not call on literature to supply a representational medium but a material that can make manifest the primitive.

By way of illustration, and to raise the curtain on the kinds of literary expression with which this study will be concerned, we can look at the cutting up and rearranging of language in the following excerpt from a poem by Césaire:

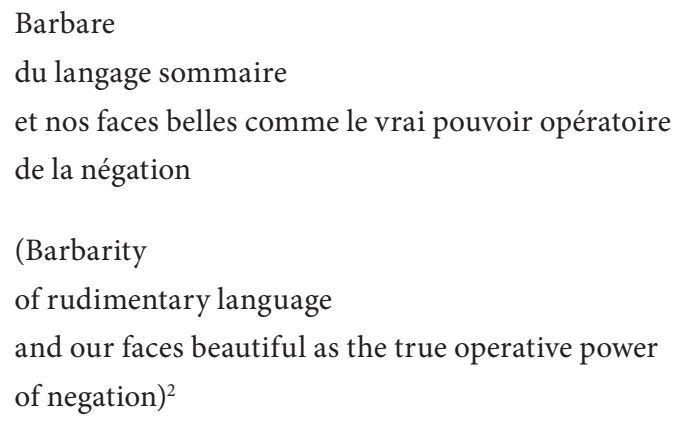

The enjambment that separates "operative power" from "of negation" has a peculiar effect on the syntax of these lines. If grammatical habit at first pushes us to read lines 3 and 4 as a single clause, the break emphasizes the syntactical parallelism of lines two and four ("of rudimentary language" and "of negation"). This might cause us to wonder whether the third line is paratactical, with the stanza reading as the beginning of a list of barbarities interrupted by a longer and incomplete statement about "our faces." The pull of the conjunctions is perhaps too strong, but the hesitation allows "barbarity" to attach itself to the final line as well as the second, an impression strengthened by further such parallelism in the next stanza. It puts into play a crisscross of equivalences that can be paraphrased: our faces are as beautiful as negation; negation is barbarous; ergo barbarity is beautiful.

There is nothing rudimentary, though, about the word rudimentary (sommaire). We might even detect the air of condescension that emanates from 
the sort of person who makes judgments about "barbarity," especially when, in the French, the half-rhyme with barbare gives it the tone of an adult playing with words for the pleasure of a child. The tinge of sarcasm is at odds with that which it proclaims. "This [i.e., barbarity] is the word that sustains me," the voice declares at the poem's outset, and when the voice later occupies the position of barbarity in the first person ("barbarity I the spitting cobra"), it arises from the incantatory wish to become barbarous. The aesthetic logic of these lines crystallizes the paradoxes of negritude, which, so goes the argument of this book, is the same as saying that it is a quintessential utterance of literary primitivism.

Négritude: a cultural movement of the black francophone middle class, which saw itself from two irreconcilable perspectives - as the civilized subject and barbarous object of European civilization-and which resolved to negate that civilization by giving itself over to its objectification as "Negro." If the "Negro" is barbarity, and barbarity negates civilization, negritude will become barbarous, says this poem. Reading on, we see that this is not purely a negation: barbarity sustains the speaker because it holds the promise of reincarnating "the dead circulating in the veins of the earth" who "smash their heads against the walls of our ears" with "screams of revolt never heard."3 Primitivism seeks out the remnants of the extinguished primitive, but its orientation is to the undeclared future. Such are primitivism's contradictions and vectors of force.

The title and subject of Césaire's poem raise the question of conceptual boundaries for a study of primitivism. Do not the terms primitive and barbarity have quite different etymologies and semantic resonances? Is this not barbarism? Throughout this book we will encounter a series of terms whose family resemblances overlap but that also have quite distinct meanings, both in our time and the period in question: primitive/primitiveness/primitivity, savage/savagery, barbarian/barbarous/barbaric, brute, primeval, archaic, primordial, even uncivilized, uncultured, native, and aboriginal. If it appears at times that I am playing loose with important linguistic distinctions and nuances, I must emphasize that this study seeks to identify the morphology (or formal structure) of the primitivist mode. As Sinéad Garrigan Mattar has commented, primitivism "is not a thing, but a process." 4 The morphology of this process centers on the relationship between what I will call, after Ernst Bloch, the nonsynchronous primitive remnant and the literary means by which this is activated. It is a dialectical relation in which the remnant is transformed by the process of its activation, and its trajectory within the work undergoes modification accordingly. It is therefore not especially important which of the terms listed above might be in play (if 
any of them are explicitly called on at all). The task is to seize on the dynamic presence of the primitivist process in the work and to understand its historic character. I retain the term primitivism partly to accord with scholarly convention, partly because it was the term used most frequently in the period on which I will focus, ${ }^{5}$ and partly because it has for some time had the widest semantic purchase.

To look squarely at primitivism's utopianism is not easy, traversing as one must the racial mediations endemic to the colonial world. It has thus become habitual simply to dismiss any artistic attempt to affirm the primitive as an act of essentialism. This may be true of many aspects of the works discussed, but we must keep in mind that utopianism aims for the nonexistent. We will see that racial representations and ideas are rarely fixed in primitivist works but tend to get discarded or transcended in the course of trying to renew the possibility of primitive experience. The coherence of the concept of primitivism rests on the structural unity of the imperial world, but this was an emphatically uneven system. I do not claim an equivalence between the modalities of primitivism that arose at different locations, within different literary spheres, and from different social positions within this totality, but I am asking why it is that the primitivist morphology articulates across the imperial totality at this time.

This study also reconsiders the politics of primitivism. If we cease to regard primitivism as a fantasy of the "Western" subject, we can no longer confine our attention to the political viewpoints of Europe and North America. There is no single answer to the question of primitivism's political valence; historical connections can be found with communism, fascism, white and black nationalism, communitarianism, and anarchism, all of which refract in unpredictable ways through the prism of aesthetic form. Across primitivist works, though, there is a common desire for a determinate negation of the world order that culminated in imperialist capitalism. This is what I will refer to as primitivism's decolonial horizon, a term to be distinguished from historical decolonization. Quite evidently, primitivism was just one form of the proliferation of radical utopianisms in the early to mid-twentieth century, though perhaps unique in its gravitation toward the perimeter of the imperial totality. I will identify primitivism's "epoch of possibility," to borrow a phrase from Rory Dufficy, which opens at the moment of finance-driven "Imperialism" (as defined contemporaneously by J. A. Hobson, Rosa Luxemburg, and others) and closes with decolonization and the hope that Third World internationalism could inaugurate an alternative social world. ${ }^{6}$ 
This book is a conceptual reappraisal of the notion of literary primitivism, and it focuses on those authorships and works that sit at its heart. Just as a study of the modernist novel will be drawn to a work of the magnitude of Ulysses or one of romanticism to The Prelude, so is there an inherent pull toward Césaire's negritude and the debates surrounding it. If the intention were to attempt a survey, I might have covered a range of less intensively primitivist works, such as we find in the primitivist strain of European surrealism or the Haitian writers who anticipated negritude. I might even have looked at a group like the selfproclaimed "Jindyworobaks," who emerged in the 1930s in Australia and for whom the injunction was to "make/ music for the / dead tribes' sake." In any case a truly encompassing study would need to look at primitivism across aesthetic media. As primitivism was neither a genre nor a school but a historically contingent aesthetic mode, its articulations do not sit within firm boundaries. There are many works in which we can perceive the primitivist impulse but that do not carry this impulse through, something that is evident in the discussion of Langston Hughes in Chapter 4. This book presents the beginnings of a new reckoning with primitivism, not its circumference.

The task of rethinking primitivism from the point of view of totality recommends itself at a time when the conditions that gave rise to it over a century ago are, in many respects, being repeated. The new realities of Imperialism produced a disconcerting claustrophobia at the start of the twentieth century. A world that hitherto had been perceived as a patchwork of incommensurate social realities suddenly appeared as a single lit-up social space, and consciousness had to cope with this absolute immanence. Our new "one world" consciousness, for which nature itself now appears subsumed into a world refitted for capitalist humans (the so-called Anthropocene), is forming at a time when the Internet is consolidating itself as humanity's sole communicative medium and commodity markets the sole means of acquiring necessary goods. We are experiencing a new, ever more extreme claustrophobia of immanence. The withering of faith in the human subject and the concomitant rise of the ideology of "posthumanism" and attendant postcreative notions of aesthetic production appear as the wishful thinking of those who feel helpless before these processes. From the perspective of capitalism's global maturation, literary primitivism reads as a prophetic scream. In meditating on its truth content we might gain perspective on the philosophical, aesthetic, and political blockages of our day. 
This project did not begin life as a general study of literary primitivism, and it was only reluctantly that I came to address such a large subject. It was not a matter of setting out to reevaluate primitivism so much as the necessity of doing so revealing itself to me as I tried to confine the study to manageable proportions. Chapter 7, which concerns the primitivist novels of Claude McKay, bears traces of an abandoned project on imperialism and literary representations of music. This morphed into a study of primitivism in the Anglophone and Francophone Caribbean when I first read Jean-Paul Sartre's "Orphée Noir," and for several years I tried to restrict the focus to this region. When I tried to explain the relation of Caribbean primitivism to primitivist writing elsewhere, however, I finally had to admit to myself that what I had thought was a Caribbean strain of the phenomenon was the thing itself and that literary primitivism in general would need to be recast.

The journey has been long, and the book is the result of critical discussions with many scholars. Priyamvada Gopal has been with the project from the start, and I hear her voice probing at the ideas as I write this tribute. Her enthusiasm and encouragement did not falter. In the other ear is the more calming voice of Adrian Poole, who nevertheless pulled the rug from under a number of certainties in the early stages. Timothy Brennan invited me to present an early draft of Part I at the University of Minnesota, and his responses gave me the confidence to take the broad view. Later, he closely scrutinized much of the manuscript, identifying significant areas that had been overlooked. Jarad Zimbler has been a stalwart friend throughout, smiling and nodding quizzically while I contradicted and then corrected myself, and doing much the same with respect to prose, which he had a great hand in sorting out. Neil Lazarus, David Trotter, Nick Nesbitt, and Nicholas Brown gave incisive critiques of the manuscript at various stages, and I have referred to their comments often even as the book moved beyond the material they critiqued. David Nowell Smith, Sean Pryor, Victor Li, Keya Ganguly, Rachel Malkin, and Georgina Born were all readers of great care. Anthony Uhlmann and Ivor Indyk have given me a welcoming home at the Writing and Society Research Centre at Western Sydney University, where this book largely has been written. I would also like to thank the following for their intellectual friendship and specific contributions that are too numerous to list: Anna Bernard, Jocelyn Betts, Rachel Bower, Leila Bright, Rory Dufficy, Kate Fagan, Damien Freeman, Josie Gill, Holly High, Simon Jarvis, Megan Jones, Sarah Milne, Warren Montag, Sascha Morrell, Desha Osborne, Elizabeth Pender, Gautam Premnath, Kate Prentice, Jeremy 
Prynne, Catherine Rashid, Joshua Robinson, Catherine Trundle, Chris Warnes, Daniel Wilson, Christopher Wortham, and Mi Zhou. Emily-Jane Cohen and her editorial team at Stanford University Press have been buoyant in communication and rigorous in their work with the manuscript.

The kinship of Robbie Wood has pervaded this project, as has the love of Maddie Kelly. To my family, Nathan Etherington, Peggy Brock, and Norman Etherington, do I owe the most-for their help and support at every stage and, above all, for cultivating the instinct to take the opposing view. 
This page intentionally left blank 
LITERARY PRIMITIVISM 
This page intentionally left blank 